\title{
Processes controlling the downstream evolution of ice rheology in glacier shear margins: case study on Rutford Ice Stream, West Antarctica
}

\author{
BRENT M. MINCHEW, ${ }^{1 *}$ COLIN R. MEYER, ${ }^{2}$ ALEXANDER A. ROBEL, ${ }^{3,4}$ \\ G. HILMAR GUDMUNDSSON, ${ }^{1}+$ MARK SIMONS ${ }^{3}$ \\ ${ }^{1}$ British Antarctic Survey, Cambridge, UK \\ ${ }^{2}$ Department of Earth Sciences, University of Oregon, Eugene, OR, USA \\ ${ }^{3}$ Seismological Laboratory, California Institute of Technology, Pasadena, CA, USA \\ ${ }^{4}$ Department of the Geophysical Sciences, University of Chicago, Chicago, IL, USA \\ Correspondence: Brent Minchew <minchew@mit.edu>
}

\begin{abstract}
Ice rheology governs how glaciers flow and respond to environmental change. The rheology of glacier ice evolves in response to a variety of mechanisms, including damage, heating, melting and the development of crystalline fabric. The relative contributions of these rheological mechanisms are not well understood. Using remotely sensed data and physical models, we decouple the influence of each of the aforementioned mechanisms along the margins of Rutford Ice Stream, a laterally confined outlet glacier in West Antarctica. We show that fabric is an important control on ice rheology in the shear margins, with an inferred softening effect consistent with a single-maximum fabric. Fabric evolves to steady state near the onset of streaming flow, and ice progressively softens downstream almost exclusively due to shear heating. The rate of heating is sensitive to local shear strain rates, which respond to local changes in bed topography as ice is squeezed through the basal trough. The impact of shear heating on the downstream evolution of ice rheology in a laterally confined glacier suggests that the thermoviscous feedback - wherein faster ice flow leads to higher rates of shear heating, further softening the ice - is a fundamental control on glacier dynamics.
\end{abstract}

KEYWORDS: Anisotropic ice flow, Antarctic glaciology, glacial rheology, glacier flow, ice rheology

\section{INTRODUCTION}

Fast-flowing ice in the Antarctic ice sheet accounts for the majority of mass transport to the oceans (e.g., Rignot and others, 2011). Fast flow is accommodated primarily by slip at the bed (Morlighem and others, 2013; Arthern and others, 2015) and restrained in part by drag in the lateral shear margins (Echelmeyer and others, 1994; Raymond, 1996; Joughin and others, 2004). Lateral shear margins are bands of intense deformation that separate relatively fastflowing ice from stagnant ice or rock (Fig. 1) and drag in shear margins is a function of the rheology of ice within the margin. The rheology evolves in response to damage, heating, melting, and the development of crystallographic fabric, each of which depend on rates of local shearing and cumulative strain (Budd and Jacka, 1989; Scambos and others, 1994; Suckale and others, 2014). Though fundamental to understanding glacier dynamics and to making reliable projections of future glacier states, our knowledge of the relative contributions of these rheological mechanisms is incomplete (Schulson and Duval, 2009; Cuffey and Paterson, 2010; Hudleston, 2015), in part because of the dearth of suitable data.

Sparse observations indicate that deformation heating warms ice at depth (Harrison and others, 1998), potentially

* Present address: Department of Earth Atmospheric and Planetary Sciences Massachusetts Institute of Technology Cambridge MA, USA.

† Present address: Geography and Environmental Sciences Northumbria University Newcastle UK. leading to the formation of temperate ice (Clarke and others, 2000), and that crystalline fabric found at depth ( $\sim 300 \mathrm{~m})$ can enhance shear deformation rates for a given shear stress (Jackson and Kamb, 1997). The existence of relatively warm ice at depth is consistent with rates of shear heating (e.g., Echelmeyer and others, 1994; Scambos and others, 1994; Perol and Rice, 2015) that are expected given the viscosity of ice (effective dynamic viscosity $\sim 10^{12}$ $\left.10^{15} \mathrm{~Pa} \cdot \mathrm{s}\right)$, high shear strain rates (e.g. Fig. 1d), and the low thermal conductivity of ice (Table 1). The existence of crystalline fabric in shear margins is consistent with laboratory (Budd and Jacka, 1989; Jacka and Budd, 1989; Vaughan and others, 2017), field (Hudleston, 1977; Smith and others, 2017) and borehole observations (Herron and Langway, 1982) showing direction-dependent softening of ice.

Mechanistic studies of shear margins often rely on observed surface velocities and models (e.g., Echelmeyer and others, 1994; Raymond, 1996; Perol and Rice, 2015; Elsworth and Suckale, 2016). These studies have illuminated numerous physical processes related to the thermomechanics of ice flow (e.g., Schoof, 2004, 2012; Hindmarsh, 2004), the hydromechanical properties of subglacial till (e.g., Kyrke-Smith and others, 2013; Robel and others, 2016; Meyer and others, 2016, 2017; Lipovsky and Dunham, 2017), the transport of subglacial till to form shear-margin moraines (Stokes and Clark, 2002; Hindmarsh and Stokes, 2008) and the detailed mechanics of the shear margin as a boundary-layer between a fast-flowing ice 

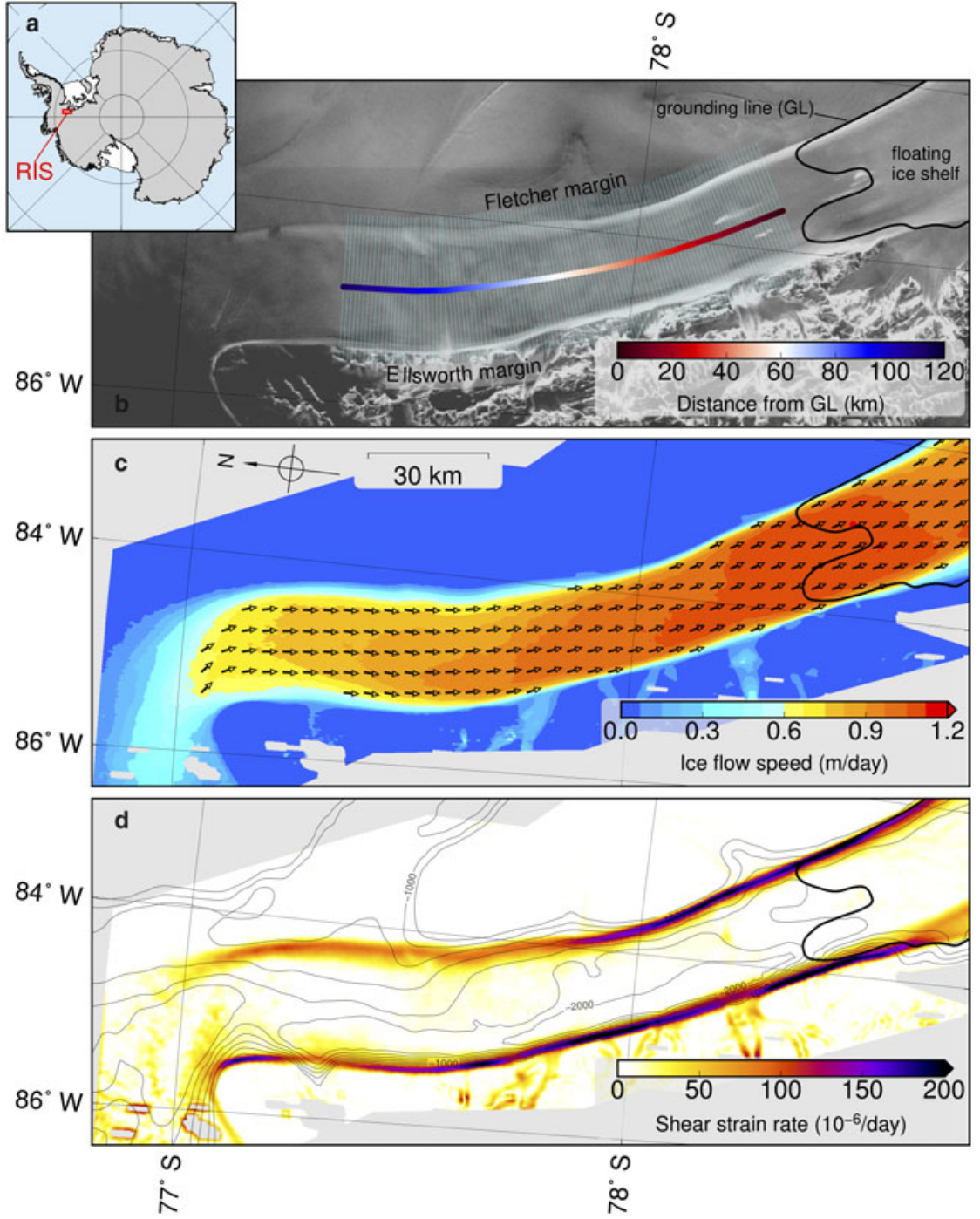

Fig. 1. Spatial characteristics of RIS. (a) Map of Antarctica showing the location of RIS and the outline of the region of interest in red. Ice shelves are shown in white and grounded ice in gray (Fretwell and others, 2013). (b) Normalized radar backscatter amplitude (grayscale) from RADARSAT-1 AMM-1 (Jezek and others, 2013) overlain by transects (cyan) and distance color scheme used in Figures 2 and 4. (c) Surface velocity (Minchew and others, 2017), where colormap indicates speed and equal-length arrows indicate flow direction. (d) Amplitude of lateral shear strain rate $\left(\dot{\varepsilon}_{\text {lat }}\right)$ overlain by thin contour lines representing basal topography below $-800 \mathrm{~m}$ elevation in 200 m increments (Fretwell and others, 2013). In (b-d), the GL is indicated by the thick, sinuous black line (Minchew and others, 2017). All maps are in South Polar Stereographic projection.

stream and the slow, convergent flow of an adjacent ice ridge (e.g., Schoof, 2012; Haseloff and others, 2015). Most of these studies highlight the importance of heating through viscous dissipation, a prominent control on ice rheology because the softness of ice varies exponentially with temperature (Cuffey and Paterson, 2010; Hudleston, 2015). Indeed, the temperature-dependence of ice rheology may give rise to thermoviscous instabilities that could help explain the formation of ice streams (Clarke and others, 1977; Fowler and Johnson, 1996; Hindmarsh, 2004, 2009).

Many studies that focus on the mechanics of ice stream shear margins take ice rheology in the margins to be constant (e.g., Schoof, 2004, 2012; Haseloff and others, 2015), while others consider the influence of temperature and macroscopic damage but not fabric or texture on ice rheology (e. g., Thompson and others, 2014; Suckale and others, 2014; Perol and Rice, 2015; Elsworth and Suckale, 2016). These studies are often focused on understanding the complex mechanisms that govern the locations of ice stream shear margins that lack obvious lateral topographic control, so a simplified treatment of ice rheology may be justified. However, fabric, which describes the preferred crystalline orientation (see Cuffey and Paterson, 2010, §3.3.4), is important for large-scale ice flow (e.g., Ma and others, 2010) and distinct from variations in temperature and melting for two important reasons: fabric induces anisotropy in ice rheology, thereby allowing ice to deform more readily in some directions than in others, and fabric tends to saturate under cumulative strains that can be reached within a few kilometers in shear margins, thereby mitigating the potential for fabric-induced dynamic feedbacks (Budd and Jacka, 1989; Jacka and Budd, 1989; Alley, 1992). Fabric development depends on the deformational history of the ice (Alley, 1988) and can take myriad complex forms with varying influences on ice rheology (Alley, 1992; Cuffey and Paterson, 2010; Smith and others, 2017). The effects of fabric are superimposed on the effects of crystal-size (texture), both of which are influenced by dynamic 
Table 1. Model parameters. Unless otherwise stated, values are from (Cuffey and Paterson, 2010)

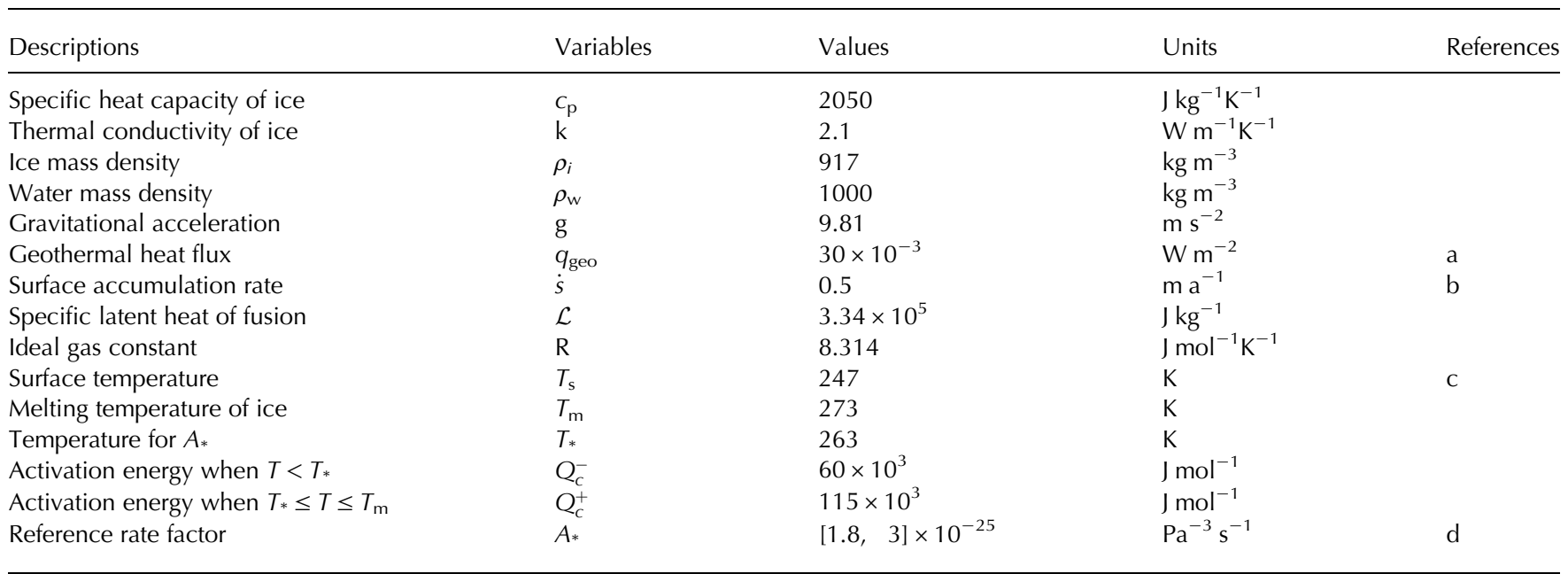

a. based on personal communication with R. Mulvaney

b. van Wessem and others (2014)

c. Doake and others (2001)

d. Macayeal and others (1998)

recrystallization, which can occur when the ice temperature approaches the melting temperature (Cuffey and others, 2000a,b; Cuffey and Paterson, 2010).

Here, we use a unique ice-velocity dataset (Minchew and others, 2017) to constrain thermomechanical and macroscopic damage models in order to decouple the mechanisms responsible for the downstream evolution of ice rheology in the margins of Rutford Ice Stream (RIS), West Antarctica (Fig. 1). Our velocity data were derived from spatially and temporally dense synthetic aperture radar observations collected with COSMO-SkyMed, a constellation of four satellites operated by the Italian Space Agency. The data resolve the surface velocity in both RIS shear margins with unprecedented spatial resolution $(\sim 100 \mathrm{~m})$ and small errors $\left(<2 \mathrm{~cm} \mathrm{~d}^{-1}\right)$, allowing us to accurately calculate shear strain rates from the velocity gradients along more than $100 \mathrm{~km}$ of the RIS margins (Minchew and others, 2017). These margins partially restrain the flow of RIS, an $\sim 2-\mathrm{km}$ thick ice stream that flows at an average speed of $\sim 1 \mathrm{~m} \mathrm{~d}^{-1}$ through a deep, relatively straight trough before draining into the Filchner-Ronne Ice Shelf (Fig. 1). The locations of the RIS shear margins are controlled by basal topography. The western margin abuts the Ellsworth Mountains - potentially resulting in an ice-on-rock interface (Doake and others, 2001; Fretwell and others, 2013) - while the eastern margin is adjacent to the Fletcher Promontory, resulting in an ice-on-ice interface (Figs 1,2). The relatively simple geometry of the trough and the control of topography on the margin position allows us to avoid the complexities inherent in understanding the locations of the margins in unconfined ice streams (e.g. Schoof, 2012; Perol and others, 2015).

\section{PHYSICAL MODELS}

Glacier ice is an incompressible, non-Newtonian viscous fluid with a power-law rheology, commonly called Glen's flow law (Glen, 1955; Goldsby and Kohlstedt, 2001; Cuffey and Paterson, 2010). As indicated by observations of the strain rate tensor components on RIS (Minchew and others, 2017, Figure S18), lateral shearing is the dominant deformation component in the shear margins of RIS and, therefore, the flow law can be approximated as (see appendix)

$$
\dot{\varepsilon}_{\text {lat }} \approx E A_{0} \tau_{\text {lat }}^{n},
$$

where $\dot{\varepsilon}_{\text {lat }}$ is the lateral shear strain rate, $\tau_{\text {lat }}$ is the lateral shear stress and $A_{0}$ is the reference rate factor for isotropic, undeformed glacier ice at $T_{0}$, the temperature of ice in the absence of shear heating. We prescribe $n=3$, a value supported by laboratory experiments and field observations (Glen, 1955; Budd and Jacka, 1989; Cuffey and Paterson, 2010).

In this study, we focus on $E$, the dimensionless, positivevalued total enhancement factor. For the purposes of this study, we consider depth-averaged values of $E$ and $A_{0}$. The enhancement factor is a convenient parameterization to account for observed strain rates that are larger than would be expected for a given stress state and ice rheology determined only by $A_{0}$ and $n=3$ (Echelmeyer and others, 1994). Values of $E$ greater than unity indicate net softening of the ice (i.e. lower viscosity for a given strain rate). We define $E$ as the product of enhancement factors representing different ice properties

$$
E=E_{\mathrm{T}} E_{\mathrm{d}} E_{\mathrm{f}}
$$

Each term in Eqn (2) corresponds to one or more mechanisms that influence ice rheology: the thermal enhancement factor $E_{\mathrm{T}}$ represents internal heating and melting; the macroscopic-damage enhancement factor $E_{\mathrm{d}}$ captures the influence of crevassing; and the fabric enhancement factor $E_{\mathrm{f}}$ accounts for the combined effects of density, crystal size (texture), along-flow crystalline orientation (fabric), microscopic fractures and impurities like dust and sediment. We lump several mechanisms into $E_{\mathrm{f}}$ because we cannot separate their individual contributions using available data. However, we will argue that crystallographic fabric is likely to be the dominant factor in $E_{\mathrm{f}}$, hence the moniker fabric enhancement factor. Fabric induces anisotropy in ice rheology, such that ice is softer in some stress directions and 


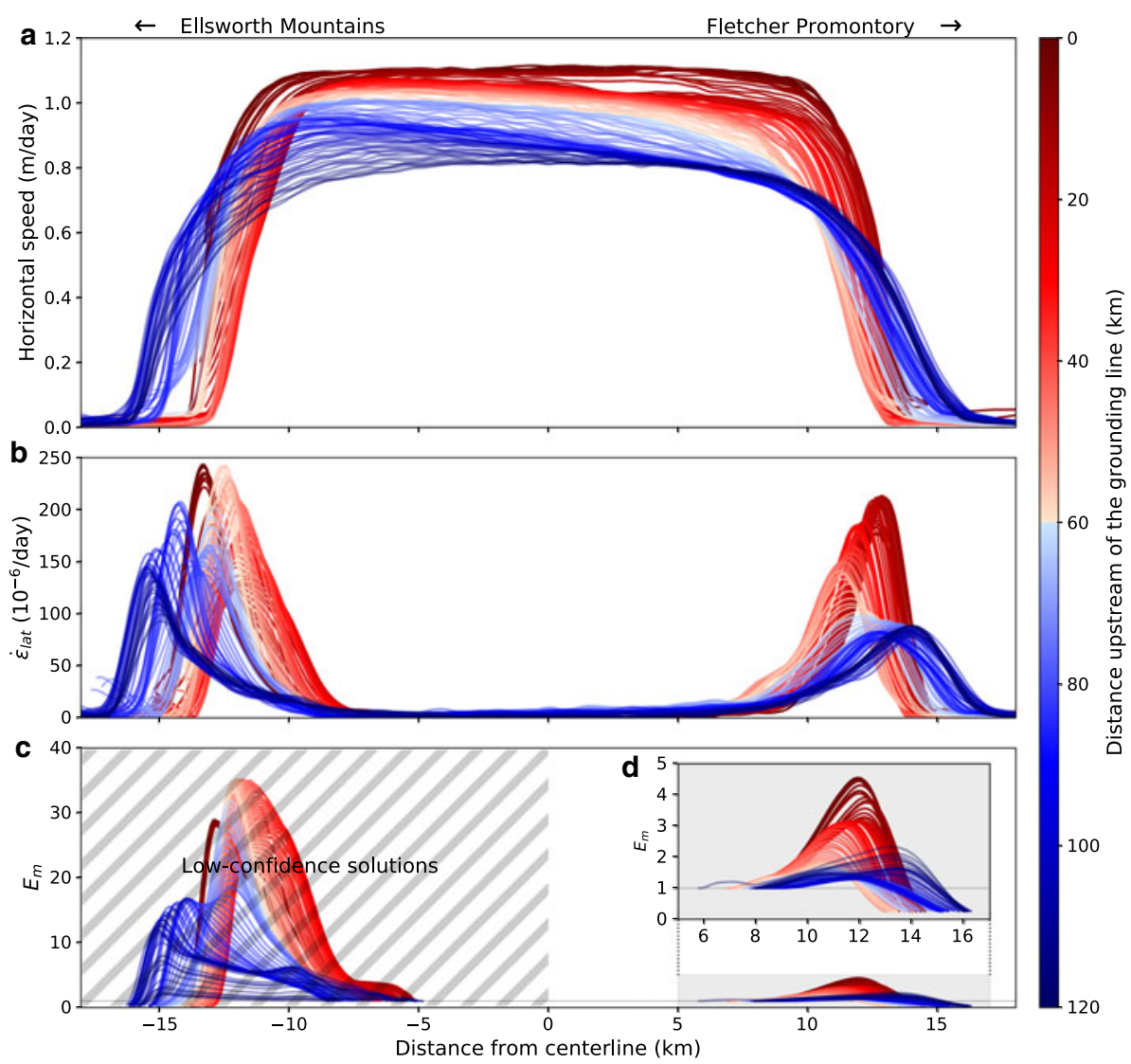

Fig. 2. Downstream variation in (a) observed horizontal surface speed, (b) lateral shear strain rate and (c, d) inferred values of $E_{\mathrm{m}} \equiv E / E_{\mathrm{f}}$ along transects shown in Figure 1b. We have low confidence in the $E_{\mathrm{m}}$ solutions in the Ellsworth margin (hatched region in panel c) because the local ice thickness is poorly constrained. Panel (d) shows a close-up view of $E_{\mathrm{m}}$ in the Fletcher margin. We use the same color scheme for all panels and show it in map view in Figure 1b. In all panels, the ice flow direction is out of the page and from blue to red in the colormap. The Ellsworth Mountains are to the left and the Fletcher Promontory is to the right.

stiffer in others. Anisotropy is captured by the scalar fabric enhancement factor $E_{\mathrm{f}}$ in the shear margins, where there is a single, dominant component of deformation (Hudleston, 2015; Cuffey and Paterson, 2010). Note that including the thermal enhancement factor $E_{\mathrm{T}}$ is a departure from the more traditional definition of $E$ as representing properties of ice separate from temperature (Cuffey and others, 2000a; Cuffey and Paterson, 2010). We make this adjustment to the definition of $E$ because we are interested in the mechanisms that soften ice in shear margins and, therefore, wish to distinguish shear heating from other heat sources.

We use several physical models to decouple the mechanisms represented inEqn (2). We will detail each model, but the main ideas are as follows: we use a macroscopic damage model to constrain the maximum value of the damage enhancement factor $E_{\mathrm{d}}$ a thermomechanical model to infer the thermal enhancement factor $E_{\mathrm{T}}$, and an ice flow model to infer the total enhancement factor $E$ absent the fabric enhancement factor $E_{\mathrm{f}}$. For convenience, we define $E_{\mathrm{m}} \equiv E / E_{\mathrm{f}}=E_{\mathrm{T}} E_{\mathrm{d}}$ to describe the enhancement factors in Eqn (2) that can be inferred with the ice flow model; for reasons we discuss later, we take $E_{\mathrm{f}}$ to be approximately constant across the margins. The thermomechanical model accounts for shear heating, which influences $E_{\mathrm{T}}$ and is sensitive to values of $E_{\mathrm{f}}$ because softening due to fabric influences the viscous dissipation rate. Thus, we take $E_{\mathrm{f}}$ to be the value that provides good agreement between inferred values of $E_{\mathrm{m}}$ (from the ice flow model) and $E_{\mathrm{T}} E_{\mathrm{d}}$ (from the thermomechanical and damage models, respectively).

\subsection{Ice flow model}

Following Echelmeyer and others (1994), we estimate the effective softening of ice in the shear margins $E_{\mathrm{m}} \equiv E / E_{\mathrm{f}}=$ $E_{\mathrm{T}} E_{\mathrm{d}}$ using the observed shear strain rates. In ice streams, it is generally the case that the flow is dominated by slip at the bed (e.g., Raymond, 1996). As a result, vertical shearing is negligible and we can apply the depth-integrated shallowshelf approximation (SSA) to the linear momentum equations. When defined in a right-hand coordinate system - with $x$ lying in the horizontal plane and parallel to the flow direction, $y$ oriented across-flow in the horizontal plane and $z$ is vertical and pointing downward - the momentum balance is given as

$$
\frac{\partial}{\partial x}\left[h\left(2 \tau_{x x}+\tau_{y y}\right)\right]+\frac{\partial}{\partial y}\left(h \tau_{x y}\right)+\tau_{\mathrm{b}}=\tau_{\mathrm{d}}
$$

there $\tau_{i j}$ are components of the deviatoric stress tensor, $\left|\tau_{x y}\right|=\tau_{\text {lat }}, \tau_{\mathrm{b}}$ is the basal shear traction, and $\tau_{\mathrm{d}}$ is the gravitational driving stress (MacAyeal, 1989, 1993). We use observed ice thickness $h$ and ice-surface slope $\alpha$ (from Fretwell and others, 2013) to calculate the gravitational driving stress $\tau_{\mathrm{d}}=\rho_{i} g h \alpha$, where $\rho_{\mathrm{i}}$ is the density of ice and $g$ is gravitational acceleration. We assume that when averaged along-flow over distances of order several ice-thicknesses, $\tau_{\mathrm{d}}$ and $\tau_{\mathrm{b}}$ covary across the flow such that $\partial\left(\tau_{\mathrm{b}} / \tau_{\mathrm{d}}\right) / \partial y \approx 0$. We justify this assumption by noting that higher $\tau_{\mathrm{b}}$ leads to steeper surface slopes, resulting in higher $\tau_{\mathrm{d}}$. Increases in $\tau_{\mathrm{b}} / \tau_{\mathrm{d}}$ near the margins, which have been inferred in previous studies (Suckale and others, 2014; Perol and Rice, 2015; 
Elsworth and Suckale, 2016), likely do not apply in our study area because the locations of RIS margins are controlled by the bed topography (Fig. 1). Applying these assumptions to Eqn (3) and neglecting the along-flow gradients of horizontal normal stresses (see Minchew and others, 2017, Figure S18), the depth-averaged lateral shear stress is given as

$$
\tau_{\text {lat }}(y)=\frac{1-\tau_{\mathrm{b}} / \tau_{\mathrm{d}}}{h} \int \tau_{\mathrm{d}} \mathrm{d} y,
$$

where $y=0$ along the centerline of the ice stream and we evaluate the integral subject to the boundary condition $\tau_{\text {lat }}=0$ at $y=0$. Applying the constitutive relation (Eqn (1)) and assuming that strain-rate is constant with depth (as in Echelmeyer and others, 1994; Perol and Rice, 2015), Eqn (4) can be rewritten as

$$
E_{\mathrm{m}}=\frac{\dot{\varepsilon}_{\mathrm{lat}} h^{n}}{\theta}\left[\int \tau_{\mathrm{d}} \mathrm{d} y\right]^{-n},
$$

where $\theta=E_{\mathrm{f}} A_{0}\left(1-\tau_{\mathrm{b}} / \tau_{\mathrm{d}}\right)^{n}$ contains only factors that are not observable and are invariant along $y$. Due to the lack of strain in the central trunk of the ice stream and the shear strain rate dependence of the processes represented by $E_{\mathrm{m}}$ we have the condition

$$
\lim _{\dot{\varepsilon}_{\mathrm{lat}} \rightarrow 0} E_{\mathrm{m}}=1 .
$$

We solve for $\theta$ as the value that allows Eqn (5) to satisfy Eqn (6) as $\dot{\varepsilon}_{\text {lat }}$ becomes small within the ice stream trunk. Recalling that $\theta$ is constant along $y$, we then solve for the cross-flow profile of $E_{\mathrm{m}}$ (cf. Echelmeyer and others, 1994).

A key assumption in Eqn (5) is that $E_{\mathrm{f}}$ is approximately uniform across-flow in the Fletcher margin. While taking $E_{\mathrm{f}}$ to be uniform across the margins, without assuming a particular value, is simply a less restrictive variant of the common practice of prescribing a spatially constant value for $E_{\mathrm{f}}$ (e.g., Jacobson and Raymond, 1998; Schoof, 2012; Suckale and others, 2014), we now further justify this assumption. Let us consider each mechanism in $E_{\mathrm{f}}$ separately. First, it is reasonable to assume that horizontal gradients in density are negligible over spatial scales of order a few $\mathrm{km}$ (the width of the margins). Second, the absence of a spatially varying source of impurities in the Fletcher margin implies that the impurity content is likely to be approximately constant across the margin. Third, based on laboratory studies (Jacka, 1984; Jacka and Budd, 1989; Cuffey and Paterson, 2010), both crystal grain size and orientation should saturate under cumulative strains $\epsilon \sim 0.15$, and a single-maximum fabric should form in simple shear under cumulative strains $\epsilon<2$ (Bouchez and Duval, 1982; Jacka and Budd, 1989). Given upstream values of $\dot{\varepsilon}_{\text {lat }} \sim 10^{-4} \mathrm{~d}^{-1}$ and typical horizontal speeds in the shear margin $\sim 0.4 \mathrm{~m} \mathrm{~d}^{-1}$ (Fig. 1), we expect the crystalline structure to evolve to near-steady-state within a few $\mathrm{km}$ downstream and to have single-maximum fabric in $\sim 10 \mathrm{~km}$. Because there are no significant alongflow changes in the orientation of the deformation field and shear strain is more concentrated (i.e. the margins narrow; see Fig. 1d) downstream, cumulative strains exceed the saturation threshold $(\epsilon \gg 2)$ across the margin within our area of interest. Thus, we expect the crystalline structure to approximate a single-maximum fabric, with a preferred $c$-axis orientation parallel to the $y$-axis, across and along the margin within our study area. This expectation is consistent with our final results that suggest that there is a single preferred crystalline orientation.

A constant fabric type does not necessarily mean that $E_{\mathrm{f}}$ is uniform across the margin because crystal size (i.e., texture) can influence rheology. Field observations show that the influence of crystal size on ice softness is small relative to the effect of fabric (Cuffey and others, 2000a,b). Crystal size saturates under strains comparable with those of fabric saturation (Jacka, 1984; Jacka and Budd, 1989), which occur far upstream in our study area. Taken together, these arguments indicate that it is reasonable to assume that the effective fabric enhancement factor $E_{\mathrm{f}}$ is approximately constant across the margins.

\subsection{Damage model}

To estimate $E_{\mathrm{d}}$, we adopt the continuum damage mechanics model of Borstad and others (2012), who define the damage enhancement factor as

$$
E_{\mathrm{d}}=\left(1-\mathrm{a}_{\mathrm{d}}\right)^{-n}
$$

where $a_{d}$ is a dimensionless damage parameter that represents the reduction in the effective load-bearing cross-sectional area (i.e. the ability of the material to withstand a load). Over a horizontal length scale $\ell>h$, the characteristic length scale for stress transmission (Gudmundsson, 2003), we expect some fraction of the ice $\lambda$ to be crevassed. Therefore,

$$
a_{\mathrm{d}}=\lambda \frac{d}{h}
$$

where $d$ is the maximum surface crevasse depth and $\lambda$ ranges between 0 for undamaged ice and 1 for crevasses that extend uninterrupted over $\ell \gg h$. Based on observations (Vaughan, 1993; Raymond and others, 2001), we assume that $\lambda<0.5$. Finally, when $d / h \ll 1$, we note that Eqn (7) reduces to $E_{\mathrm{d}} \approx$ $1+n a_{\mathrm{d}} \approx 1+n \lambda d / h$.

The shear margins on RIS are extensively crevassed (Vaughan, 1993; Doake and others, 2001). We expect surface crevassing to be the only important macroscopic damage mechanism in our study area because persistent basal crevasses predominantly exist only where ice is at or near floatation (Van der Veen, 1998a), which is not the case in our study area (Doake and others, 2001; Joughin and others, 2006). To estimate the maximum surface crevasse depth, $d$, we use the Nye model (Nye, 1957), chosen because it is a simple damage model that provides plausible estimates of crevasse depth (Mottram and Benn, 2009). In the Nye model, $d$ is the depth at which the tensile stress (mode I crack) is balanced by hydrostatic pressure, such that

$$
2 \tau_{1}=\rho_{i} g d
$$

where $\tau_{1}$ is the principal tensile stress. Since our goal is to constrain the maximum crevasse depth, we neglect the fracture toughness of ice (Van der Veen, 1998b,a; Mottram and Benn, 2009), thereby allowing ice to fracture under any nonzero stress. We further note that crevassing in the RIS margins occurs in both tension and compression (Vaughan, 1993) and that fractures can result from shearing (crack modes II and III). Therefore, we adopt the von Mises 
yield criteria and replace the tensile stress in the Nye model with the von Mises stress $\tau_{\mathrm{v}}=\sqrt{3} \tau_{\mathrm{e}}$, where $\tau_{\mathrm{e}}=\sqrt{\tau_{i j} \tau_{i j} / 2}$ is the effective deviatoric stress. From Glen's Law (Eqn (A1)), we find that $\tau_{v}=\sqrt{3}\left(\dot{\varepsilon}_{e} /\left(E A_{0}\right)\right)^{1 / n}$, where $\dot{\varepsilon}_{e}=\sqrt{\dot{\varepsilon}_{i j} \dot{\varepsilon}_{i j} / 2}$ is the effective strain rate, $\dot{\varepsilon}_{i j}$ is the strain rate tensor and $\left|\dot{\varepsilon}_{x y}\right|=\dot{\varepsilon}_{\text {lat }}$. When shearing is the dominant deformation regime, as it is on RIS (Minchew and others, 2017), $\dot{\varepsilon}_{\mathrm{e}} \approx \dot{\varepsilon}_{\text {lat, }}$ yielding the maximum crevasse depth

$$
d \approx \frac{2 \sqrt{3}}{\rho_{i} g}\left(\frac{\dot{\varepsilon}_{\text {lat }}}{E A_{0}}\right)^{1 / n} .
$$

To estimate the maximum crevasse depth $d$, and by extension maximum $E_{\mathrm{d}}$, we make two assumptions when calculating the values shown in Fig. 3c. First, we prescribe
$E=1$, noting that any value of $E$ greater than unity would reduce $E_{\mathrm{d}}$ by reducing $d$ by a factor of $E^{-1 / n}$. In the results, we show that $E_{\mathrm{d}} \approx 1$ even though we set $E$ to unity in Eqn (10); we can expect the actual values for $E_{\mathrm{d}}$ to be closer to unity, which strengthens our conclusion that macroscopic damage is negligible on RIS. Second, we take $A_{0}$ to be the value of $A$ evaluated at the surface temperature $T_{\mathrm{S}}$ using the Arrhenius relation discussed in the next section. By using surface temperature, we are not explicitly treating the possibility that cold-air ponding can decrease the air temperature in crevasses, thereby decreasing $A_{0}$ by a factor of $\sim 3$ (i.e., increasing $d$ by a factor of $3^{1 / 3} \approx 1.4$ ) for values taken in an ice stream shear margin on the Siple Coast, West Antarctica (Harrison and others, 1998). For the small values we infer for $\mathrm{d} / \mathrm{h}$, ignoring the cold-air ponding effect introduces an error in $E_{\mathrm{d}}$ of $\sim 4 \%$.
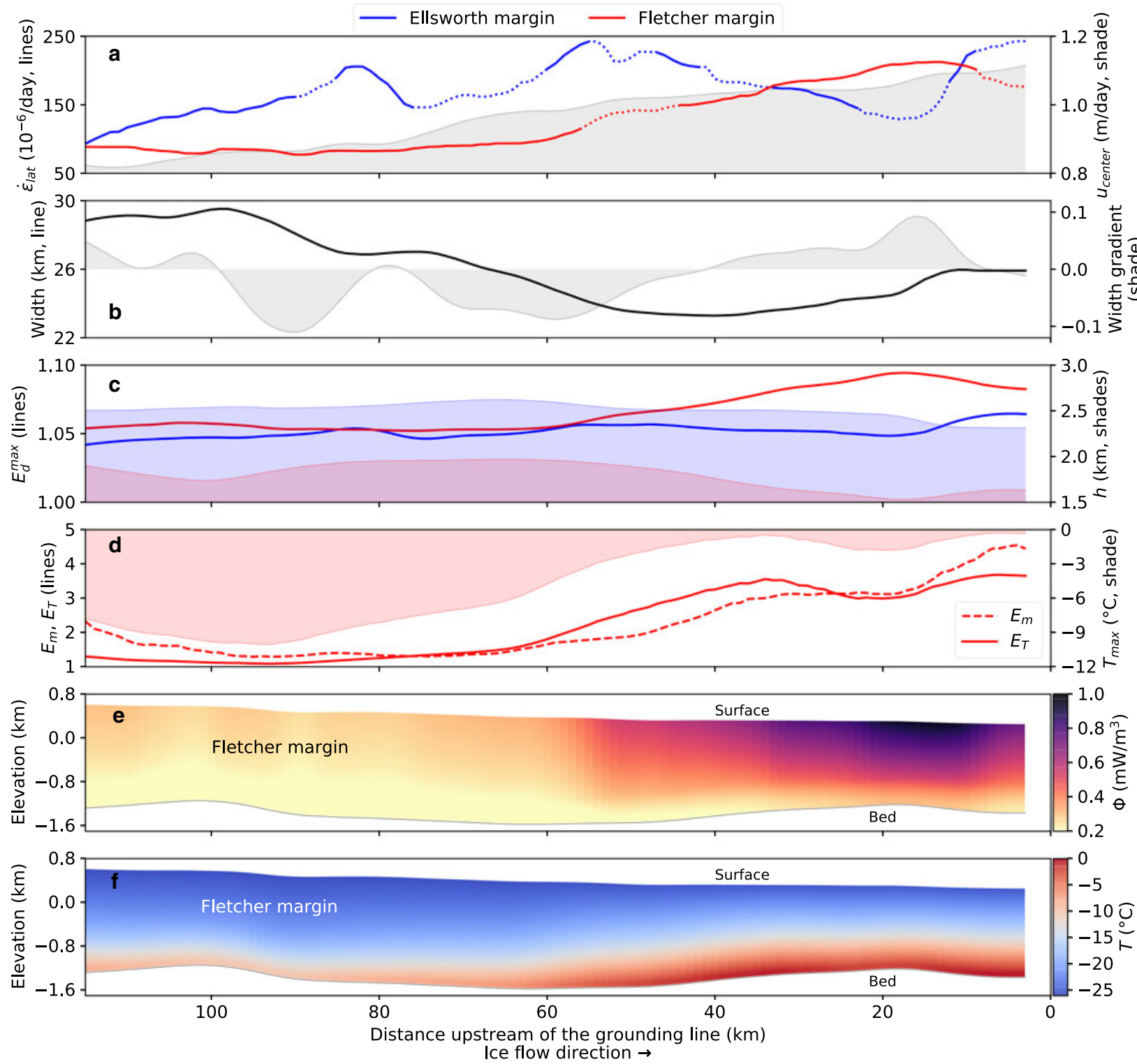

Fig. 3. Along-flow variations in the Ellsworth (blue) and Fletcher (red) margins of RIS. (a) Lateral shear strain rates (lines) and horizontal speed along the centerline (gray shade). Dashed line segments occur where tributary glaciers intersect RIS (Fig. 1b). (b) Total RIS width (black line) and along-flow gradient of width (gray shade). We define width to be the distance between strain-rate maxima in each margin (Fig. 2b). (c) Maximum macroscopic-damage enhancement factor $E_{\mathrm{d}}^{\max }$ (lines) and ice thickness $h$ in the margins (shaded regions). (d) Thermal, $E_{\mathrm{T}}$, (solid line) and margin, $E_{\mathrm{m}}$ (dashed line) enhancement factors overlaying inferred maximum (basal) ice temperature (shaded region). All values for $E_{\mathrm{T}}$ and $\mathrm{T}$ are calculated using $E_{\mathrm{f}} A_{*}=18$ (see Table 1 for $A_{*}$ values). (e) Steady-state rates of shear heating, $\Phi$, and (f) ice temperature with elevation defined relative to mean sea level. For reference, $1 \mathrm{~mW} / \mathrm{m}^{3} \approx 16.7 \times 10^{-3}{ }^{\circ} \mathrm{C} \mathrm{a}{ }^{-1}$, using values given in Table 1. We show only the Fletcher margin in $(d-f)$ because ice thickness is poorly constrained in the Ellsworth margin. 


\subsection{Thermomechanical model}

The softness of ice depends on temperature $T(z)$ and water content $\phi(z)$, where $\phi$ is the porosity in temperate ice and we have assumed that pore spaces will be saturated (Meyer and Hewitt, 2017). Both temperature and water content are depth-dependent; we combine their effects and average over depth to get $E_{\mathrm{T}}$. Taking ice softness to be a function of local ice temperature, the depth-averaged thermal enhancement factor $E_{\mathrm{T}}$ is given as

$$
E_{\mathrm{T}}=\frac{1}{h} \int_{0}^{h} E_{\mathrm{w}} \frac{A_{\mathrm{T}}}{A_{0}} \mathrm{~d} z
$$

The enhancement factor due to liquid water content $E_{\mathrm{w}}=$ $E_{\mathrm{w}}(\phi(z))$ can be approximated as (Duval, 1977; Lliboutry and Duval, 1985; Cuffey and Paterson, 2010)

$$
E_{\mathrm{w}}=1+200 \phi
$$

and accounts for lubrication of the ice crystals by interstitial water content. The temperature-dependent rate factor $A_{\mathrm{T}}=$ $A_{\mathrm{T}}(T(z))$ can be empirically represented by an Arrhenius relation defined as

$$
A_{\mathrm{T}}=A_{*} \exp \left\{-\frac{Q_{\mathrm{C}}}{R}\left(\frac{1}{T_{*}}-\frac{1}{T}\right)\right\}
$$

where $R$ is the ideal gas constant, $A_{*}$ is the value of $A$ for isotropic and undeformed ice at $T=T_{*}$,

$$
Q_{C}=\left\{\begin{array}{ccc}
Q_{C}^{-} & \text {if } & T<T_{*} \\
Q_{C}^{+} & \text {if } & T_{*} \leq T \leq T_{\mathrm{m}}
\end{array}\right.
$$

is the activation energy, $T_{*}$ is the temperature at which $Q_{c}$ changes value and $T_{\mathrm{m}}$ is the melting temperature of ice, which we take to be independent of depth (further details in Cuffey and Paterson, 2010, §3.4.6). All parameter values are given Table 1 and we note that we use a range of values for $A_{*}$ based on studies conducted near RIS (Macayeal and others, 1998; Cuffey and Paterson, 2010).

The strong dependence of $E_{\mathrm{T}}$ on temperature and water content means that shear heating plays an important role in setting the rheology of ice in areas with high shear strain rates. Shear heating arises from viscous dissipation, the irreversible conversion of kinetic energy to heat that occurs when a viscous fluid deforms. When ice is below the melting temperature, shear heating warms the ice, causing the ice to soften (increase $E_{\mathrm{T}}$ ). When ice is temperate, it is a mixture of ice and water that is at the melting temperature. Ice remains viscous even at its melting temperature and thus temperate ice generates heat when deformed. This heat melts the ice, thereby increasing the interstitial water content and further softening the ice (increasing $E_{\mathrm{T}}$ ) by allowing individual crystals to slip along their boundaries with less friction (Duval, 1977; Lliboutry and Duval, 1985).

To estimate the depth-dependent temperature and meltwater production and transport, we adopt the model of Schoof and Hewitt (2016). This model is capable of capturing the transition from cold to temperate ice along with the production of meltwater in temperate ice. The model includes advection, diffusion, shear heating as an internal heat source, meltwater production and meltwater transport that adheres to Darcy's Law. We solve the model in one vertical dimension (1-D), listing all parameter values in Table 1.
In the Results section, we show that a temperate zone is unlikely to exist in our study area, meaning that the melt rate $\dot{m}=0, \phi=0$ and $E_{\mathrm{w}}=1$ everywhere. In the following derivation, we retain the model terms related to meltwater production and ice softening due to water content for completeness but discuss only the salient features of the model for brevity. A more detailed summary of the model can be found in Hewitt and Schoof (2017).

We focus our analysis on the Fletcher shear margin, where we can make some simplifications to the energy balance. First, by considering observed ice thickness and surface slope, we estimate rates of lateral advection of cold ice into the margin from outside the ice stream to be $u_{y} \ll 0.1 \mathrm{~m} \mathrm{a}^{-1}$. This advection rate was found by Suckale and others (2014) to have a negligible influence on thermomechanical effects in a shear margin with values of shear strain rate and ice thickness comparable with the Fletcher margin. Thus, we neglect lateral advection of cold ice into the margins. Second, in line with numerous studies of deformation-induced heating in lateral shear margins (e.g., Echelmeyer and others, 1994; Jacobson and Raymond, 1998; Schoof, 2004, 2012; Perol and Rice, 2015; Suckale and others, 2014), we also neglect along-flow advection and provide further justification for this assumption in the discussion section. Then, by considering only vertical diffusion (Schoof and Hewitt, 2013), we can express the reduced form of energy conservation as

$$
\rho_{i} c_{\mathrm{p}}\left(\frac{\partial T}{\partial t}+u_{z} \frac{\partial T}{\partial z}\right)=k \frac{\partial^{2} T}{\partial z^{2}}+\Phi-\rho_{\mathrm{w}} \mathcal{L} \dot{m}
$$

where $T$ is the ice temperature, $\Phi$ is the viscous dissipation function, $c_{\mathrm{p}}$ is the specific heat capacity of ice, $k$ is the spatially constant thermal conductivity of ice, $\rho_{\mathrm{w}}$ is the mass density of meltwater, $\mathcal{L}$ is the specific latent heat of fusion and $\dot{m}$ is the melt rate. We adopt the common assumption that the downward advection of ice is linearly dependent on depth and snow accumulation rate, with maximum values at the surface and zero at the bed such that

$$
u_{z}=\dot{s}\left(1-\frac{z}{h}\right)
$$

where $\dot{s}$ is the surface accumulation rate (Clarke and others, 1977; Echelmeyer and others, 1994; Perol and Rice, 2015). Based on the results of a regional climate model (van Wessem and others, 2014), we take the surface accumulation rate to be spatially constant.

In areas where lateral shearing is the dominant component of deformation, the depth-dependent rate of shear heating is

$$
\begin{aligned}
\Phi & =\dot{\varepsilon}_{i j} \sigma_{i j} \\
& \approx 2 \dot{\varepsilon}_{\text {lat }} \tau_{\text {lat }} \\
& \approx 2\left(\frac{\dot{\varepsilon}_{\text {lat }}^{n+1}}{E_{\mathrm{f}} E_{\mathrm{d}} E_{\mathrm{w}} A_{\mathrm{T}}}\right)^{1 / n},
\end{aligned}
$$

where $\sigma_{i j}$ is the Cauchy stress tensor. We drive the model in Eqns (15)-(17) to steady state using a forward Euler, finitevolume method, subject to the boundary conditions:

$$
\begin{gathered}
T=T_{\mathrm{s}} \quad \text { at } \quad z=0, \\
-k \frac{\partial T}{\partial z}=q_{\text {geo }} \quad \text { at } \quad z=h,
\end{gathered}
$$


where $T_{\mathrm{s}}$ is the surface temperature taken from measurements collected in shallow boreholes (Doake and others, 2001), and $q_{\text {geo }}$ is the geothermal heat flux taken from borehole measurements collected on the Fletcher Promontory ( $R$. Mulvaney, personal communication). We take $T_{\mathrm{s}}$ and $q_{\text {geo }}$ to be spatially constant.

To solve for $\dot{m}$ and $\phi$, the model needs to account for the production and drainage of meltwater in a temperate zone as well as changes to the basal boundary condition (Eqn (19)). In a steady-state temperate zone, the ice is at the melting temperature throughout and the rate of meltwater production balances the viscous dissipation rate such that $\dot{m}=$ $\Phi /\left(\rho_{w} \mathcal{L}\right)$ from Eqn (15). To capture the transition from cold to temperate ice, the model utilizes an enthalpy formulation and Darcy's Law is applied to calculate drainage within a temperate zone. However, our results indicate that $T<T_{\mathrm{m}}$ within our study area, meaning that there is no temperate ice zone and $\dot{m}=0, \phi=0$, and $E_{\mathrm{w}}=1$ everywhere. Thus, in the interest of brevity, we end here the derivation of the thermomechanical model as the details of the enthalpy formulation and the drainage model are not germane to this study. The enthalpy formulation and applications of Darcy's Law are derived by Schoof and Hewitt (2016) and further discussed by Hewitt and Schoof (2017). As these authors show, when the temperature remains below the melting temperature, the enthalpy formulation reduces to Eqn (15) with $\dot{m}=0$.

\section{OBSERVATIONAL DATA}

We use previously published data that are publicly available through their respective publications. Data on ice geometry are from Fretwell and others (2013) and the velocity fields are from Minchew and others (2017). Building on methods developed for airborne interferometric synthetic aperture radar observations (Minchew and others, 2015, 2016), the velocity fields used in this study were derived from synthetic aperture radar data collected from ascending and descending orbits along 32 unique flight tracks with COSMO-SkyMed, a 4-satellite constellation operated by the Italian Space Agency. These data span 9 months and yielded 1644 correlated displacement fields over RIS. All displacement fields have $\sim 100 \mathrm{~m}$ spatial resolution and were stacked to allow for inferences of the 3-D, time-dependent velocity fields (Minchew and others, 2017). Here, we utilize the horizontal secular (time-averaged) velocity fields.

We extracted data along 112 transects that are orthogonal to the ice flow direction, span the entire ice stream width and are spaced $1 \mathrm{~km}$ apart as measured along the local flow vector (Fig. 1a). The most downstream transect is $\sim 3 \mathrm{~km}$ upstream of the point where RIS first crosses the grounding line (GL) (i.e. the inland extent of the GL). We limit our region of interest to $<120 \mathrm{~km}$ upstream of the GL to stay within the region with the highest data quality (Minchew and others, 2017). From the transects of horizontal speed, we calculated the lateral shear strain rates by using a second-order SavitzkyGolay filter and a $2 \mathrm{~km}(\approx h)$ window. The Savitzky-Golay filter is an efficient method for fitting piecewise polynomials of a given order within a window of given size.

\section{RESULTS AND DISCUSSION}

All of the mechanisms represented by the various enhancement factors in Eqn (2) can be influenced by bed topography because of their dependence on cumulative strain and strain rate. RIS flows through a well-defined subglacial trough (Fig. 1). As the ice flows, it is squeezed between highs in the bed topography on either side (Figs 1c and 2). Taking RIS width to be the cross-stream distance between maximum shear strain rates in each margin, we can see that RIS narrows by $\sim 6 \mathrm{~km}(\approx 25 \%$ of the total width) in the downstream direction between 120 and $40 \mathrm{~km}$ upstream of the GL (UGL), where the GL is the boundary between grounded and floating ice. In the final $40 \mathrm{~km}$ UGL, RIS widens by $\sim 3 \mathrm{~km}$ (Fig. 3b). Along the Ellsworth margin, the encroachment of the Ellsworth Mountains into the path of the flow causes the ice to be compressed against the mountains, leading to variations in both amplitude and cross-stream position of maximum shear strain rates (Figs 2b and 3a). In the Fletcher Margin, shear strain rates increase as the ice stream slowly widens and flow accelerates following the encroachment of the Fletcher Promontory at $\sim 60 \mathrm{~km} \mathrm{UGL} \mathrm{(Figs} 1 \mathrm{c}$ and $2 \mathrm{~b}$ ). The result is a roughly monotonic increase in shear strain rates in the Fletcher margin for $\sim 50 \mathrm{~km}$ (Fig. 3a).

We use the observed strain rates to infer $E_{\mathrm{m}}$ for each data transect using Eqn (5) (Figs 2c-d). The shapes of the inferred $E_{\mathrm{m}}$ profiles reflect the shapes of the strain rate profiles (Fig. 2c), with maximum values of $E_{\mathrm{m}}$ generally increasing downstream. In the Fletcher margin, the most substantial changes in ice rheology begin $\sim 60 \mathrm{~km} U \mathrm{GL}$, coincident with increases in shear strain rate (Fig. 3). Recalling that $E_{\mathrm{m}} \equiv E / E_{\mathrm{f}}$, these results indicate continuous softening of ice in the Fletcher margin from $E \approx 1.25 E_{\mathrm{f}}$ to a maximum of $E \approx 4.5 E_{\mathrm{f}}$ near the GL. In the Ellsworth margin, where we have low confidence in inferred $E_{\mathrm{m}}$ values due to the poor constraints on ice thickness, $E$ could be as much as $5-10$ times larger than in the Fletcher margin (Figs 2c) owing to the likelihood that the ice in the Ellsworth margin is hundreds of meters thicker than ice in the Fletcher margin (Fig. 3c). The relationship between ice thickness and $E_{\mathrm{m}}$ can be seen in Eqn (5), which indicates that, for given values of $\dot{\varepsilon}_{\text {lat }}, E_{\mathrm{m}} \propto h^{n}$.

Shearing in the margins causes extensive surface crevassing that is apparent as light-colored bands in the radar backscatter amplitude image (Fig. 1a) and from field observations (Vaughan, 1993). Our calculations of $d$ (Eqn (10)) from the observed strain rates indicate that $d<100 \mathrm{~m}$ and $d / h<$ 0.06 along both margins, where $h$ is the local ice thickness (Fig. 3c). To estimate the maximum damage enhancement factor $E_{d}^{\max }(\operatorname{Eqn}(7))$, we prescribe the maximum value of $a_{\mathrm{d}}=0.5 \mathrm{~d} / \mathrm{h}$ and find that $1 \leq E_{\mathrm{d}} \leq E_{\mathrm{d}}^{\max }<1.1$ with a mean along-flow value of $\bar{E}_{\mathrm{d}}^{\max } \approx 1.05$ (Fig. 3c). These results suggest that damage plays a negligible role in the evolution of ice rheology along both RIS margins. Given the shallow depths of surface crevasses relative to the ice thickness, the conclusion that damage has a negligible influence on ice rheology should apply to the grounded portions of most of the major outlet glaciers and ice streams in Antarctica (cf., Suckale and others, 2014).

The key to decoupling the thermal $\left(E_{\mathrm{T}}\right)$ and fabric $\left(E_{\mathrm{f}}\right)$ enhancement factors is in the viscous dissipation function $\Phi$ (Eqn (17) and Fig. 3e). Lateral shearing is dominant in the RIS margins, so the rate of deformation heating is proportional to the product of lateral shear stress and strain rate. After applying the flow law (Eqn (1)), it becomes clear that the rate of shear heating depends on all of the rheological mechanisms described by the total enhancement factor $E$ (see Eqn (17)). Softening of ice caused by the development 
of crystallographic fabric (increasing $E_{\mathrm{f}}$ ), reduces the work rate needed to deform the ice at the observed rates. As a result, the rate of shear heating decreases as $E_{\mathrm{f}}$ increases, which influences the temperature profile in the ice, resulting in smaller values of the thermal enhancement factor $E_{\mathrm{T}}$ for a given strain rate. The dependence of shear heating on $E_{\mathrm{f}}$, combined with the fact that we independently infer $E_{\mathrm{m}}=$ $E_{\mathrm{d}} E_{\mathrm{T}}$ from an ice flow model (Eqn (5)), allows us to infer $E_{\mathrm{f}}$. Because damage has a negligible influence on ice rheology, $E_{\mathrm{d}} \approx 1$ and $E_{\mathrm{m}} \approx E_{\mathrm{T}}$. Only the values of thermal enhancement factor $E_{\mathrm{T}}$ calculated from the thermomechanical model (Eqn (11)) have a direct dependence on fabric $\left(E_{\mathrm{f}}\right)$, via the dissipation function $\Phi\left(\right.$ Eqn (17)); inferred values of $E_{\mathrm{m}}$ do not depend on $E_{\mathrm{f}}$. Thus, we take $E_{\mathrm{f}}$ to be the value that minimizes the difference between $E_{\mathrm{m}}$, inferred from the ice flow model (Eqn (5)), and $E_{\mathrm{T}}$, inferred from the thermomechanical model (Eqn (11)) at the location of maximum shear strain rate along each transect in the Fletcher margin, where ice thickness is well-constrained. We find that $6 \leq E_{\mathrm{f}} \leq 10$ for a range of reasonable values for other rheological parameters (Table 1). This range of $E_{\mathrm{f}}$ values is consistent with laboratory measurements of single-maximum fabric (cf. Hudleston, 2015, Figure 3) and provides good agreement between $E_{\mathrm{m}}$ and $E_{\mathrm{T}}$ along the length of study area (solid and dashed lines in Fig. 3d).

The temperature (Figs $3 \mathrm{f}$ and 4 ) and dissipation function profiles (Fig. 3e) inferred from the 1-D thermomechanical model provide a useful basis for discussing our assumption that along-flow advection is negligible in the shear margins. Temperature increases with depth and with alongflow distance at a given depth. As a result, along-flow advection will transport relatively cold ice to a given location. Colder ice is stiffer (i.e., $A_{\mathrm{T}}$ will increase), which drives an

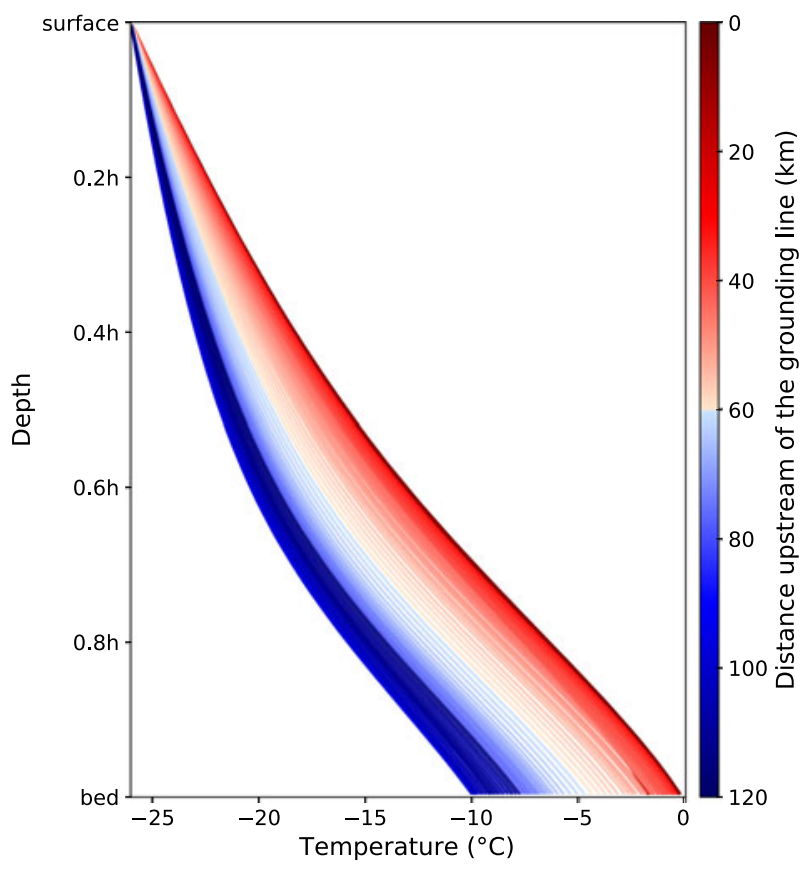

Fig. 4. Inferred vertical temperature profile in the Fletcher margin for transects shown in Fig. 1b. The vertical dimension is given as a function of ice thickness $h$, and the color scheme is the same as in Figs $1 \mathrm{~b}$ and 2. Maximum values correspond to values shown in Fig. 3d and the profiles are the same as in Fig. 3e. The surface temperature is set to the mean annual atmospheric temperature of $-26^{\circ} \mathrm{C}$ (Doake and others, 2001). increase in the rate of shear heating that acts to offset the effects of along-flow advection and to diminish the local along-flow temperature gradient. Thus, we expect the dominant terms in the energy balance to be vertical advection and viscous dissipation, which are captured by our 1-D steadystate model. Furthermore, values of $E_{\mathrm{m}}$ and $E_{\mathrm{T}}$, which are derived from independent models, are in good agreement in the along-flow direction, thereby supporting our assumption of negligible along-flow advection.

The along-margin agreement between $E_{\mathrm{m}}$ and $E_{\mathrm{T}}$ for a single value of $E_{\mathrm{f}}$ indicates that $E_{\mathrm{f}}$ remains approximately constant downstream. This conclusion is consistent with laboratory observations that show that fabric saturates under cumulative strain values $(\epsilon \sim 0.15)$ that are reached in the RIS margins within a few kilometers of the onset of flow (Jacka and Budd, 1989). Deformation in the Fletcher margin is consistent with simple shear (Minchew and others, 2017), which can lead to the formation of multiplemaximum fabric, like that observed by Jackson and Kamb (1997) in the shear margin of a different ice stream, when crystals rotate and dynamically recrystallize under strains $\epsilon<1$ (Jacka and Budd, 1989; Cuffey and Paterson, 2010). Laboratory experiments show that under higher strains $(\epsilon>$ $2)$, crystal rotation weakens the second maximum, potentially to the point of vanishing, and causes the fabric to tend toward a single maximum (Bouchez and Duval, 1982; Jacka and Budd, 1989; Cuffey and Paterson, 2010). For values of observed $\dot{\varepsilon}_{\text {lat }} \sim 10^{-4} \mathrm{~d}^{-1}$ and typical horizontal speeds in the shear margin $\sim 0.4 \mathrm{~m} \mathrm{~d}^{-1}$ (Figs 1 and 2), we expect strains $\epsilon>2$ within $\sim 10 \mathrm{~km}$ of streaming flow, supporting our inference of $E_{\mathrm{f}}$ values consistent with a singlemaximum fabric.

Of all the mechanisms accounted for in the fabric enhancement factor $E_{\mathrm{f}}$, we propose that the development of crystallographic fabric is dominant in the Fletcher margin. Several lines of evidence support this hypothesis. Perhaps most notably is that our inferred range of $6 \leq E_{\mathrm{f}} \leq 10$ is consistent with laboratory measurements (e.g., Hudleston, 2015) and field observations on RIS (Smith and others, 2017) of crystallographic fabric. Furthermore, the Fletcher margin has an ice-on-ice interface with no significant source of sediment or other impurities, and the influence of density and grain size variations on ice rheology is negligible below the depth of the firn layer (Budd and Jacka, 1989; Cuffey and Paterson, 2010), which is $\sim 10 \%$ of the thickness of RIS (Smith and others, 2017). As a result, density variations should have a negligible influence, rendering crystalline structure as the dominant mechanism in $E_{\mathrm{f}}$.

If the strength of fabric $\left(E_{\mathrm{f}}\right)$ is constant along the margin and the influence of damage is negligible, then shear heating is the only mechanism that can drive variations in ice rheology over mesoscales (spatial scales of order tens of kilometers). The general along-flow trend in temperature is reflected in both the thermal $\left(E_{\mathrm{T}}\right)$ and margin $\left(E_{\mathrm{m}}\right)$ enhancement factors (Figs $3 \mathrm{~d}-3 \mathrm{f}$ ), indicating that shear heating is the primary mechanism for the mesoscale evolution of ice rheology within $100 \mathrm{~km}$ UGL. Inferred maximum temperatures, $T_{\max }$, are located at the bed and generally increase as a function of distance downstream (Figs 3d, 3f, and 4). The vertical temperature profile retains the same general shape along the margin (Perol and Rice, 2015) and is skewed toward warmer temperatures closer to the $\mathrm{GL}$, reflecting increases in the maximum temperature caused by higher rates of shear heating (Fig. 4). Within $60 \mathrm{~km} \mathrm{UGL,} \mathrm{maximum}$ 
temperatures increase by $\sim 6^{\circ} \mathrm{C}$ and approach the melting temperature near the GL. Our results indicate that there is no significant meltwater production nor zone of temperate ice on RIS, though we note that these results apply only within the Fletcher margin and that basal temperatures within the trunk of RIS are likely at the melting temperature (Doake and others, 2001). Due to the lack of a temperate zone within the margin, temperature changes and fabric are the dominant mechanisms influencing ice rheology over short $(\sim 10 \mathrm{~km})$ and long $(\sim 100 \mathrm{~km})$ spatial scales, respectively.

The dominance of shear heating in driving mesoscale variations in ice rheology illuminates a positive, thermomechanical feedback in glaciers with topographically controlled widths. Glaciers can accelerate for a variety of reasons, such as subglacial hydrological feedbacks (e.g., Robel and others, 2013, 2014) or reductions in buttressing stresses that can occur when ice shelves collapse or are thinned by warm ocean water (Scambos and others, 2004; Dupont and Alley, 2005; Joughin and others, 2012; Mouginot and others, 2014). Faster flow speeds will generate higher shear strain rates in the margins, leading to enhanced shear heating (softer ice) and further accelerations. This feedback is related to thermoviscous processes that have been studied in ice streams with near-planar bed geometries (Jacobson and Raymond, 1998; Schoof, 2012), and invoked to explain the formation of laterally unconfined ice streams via creep (Robin, 1955; Clarke and others, 1977) and fingering instabilities (e.g., Payne and others, 2000; Hindmarsh, 2004, 2006, 2009; Brinkerhoff and Johnson, 2015). Some of the work on thermoviscous instabilities has focused on the ice near the bed (e.g., Clarke and others, 1977; Fowler and others, 2009), but the fundamental mechanisms are the same as for shear margins. And though thermoviscous instabilities have been discounted as a candidate surge mechanism in mountain glaciers (e.g., Fowler and others, 2009), the potential for thermal runaway through viscous dissipation in laterally confined ice streams is, to our knowledge, an unexplored question, and one that could have important ramifications for future projections of sea-level rise. Our results indicate that thermoviscous feedbacks are an important mechanism in the evolution of glaciers flowing through bedrock channels and their response to changes at the ice/ocean interface (e.g., Joughin and others, 2014). Furthermore, our results indicate that thermoviscous effects help explain the downstream evolution of the velocity profile, from a plane Poiseuille flow upstream to a horizontal plug flow near the grounding zone (Pearson, 1977; Ockendon, 1979), as seen in Fig. 2a. Since glacier flow governs the rate of mass loss from the Antarctic and Greenland ice sheets, this thermomechanical feedback could play a key role in the evolution of continental ice sheets.

\section{CONCLUSION}

We developed a new approach for using state-of-the-art remote-sensing data to understand the fundamental mechanisms that drive the spatial evolution of ice rheology in glacier shear margins. The broad spatial coverage, fine resolution and low noise provided by the data allowed us to decouple, for the first time, the influence of all known, prominent mechanisms that drive the evolution of ice rheology: the development of crystalline fabric, fracturing and heating. In our study area, and likely most Antarctic ice stream shear margins, surface crevassing plays a negligible role in the evolution of ice rheology because surface crevasses are shallow relative to the depth of the ice column. The crystalline fabric has a significant influence on ice rheology - softening the ice by approximately an order of magnitude - but evolves to steady state within a few kilometers of the onset of streaming ice flow. Shear heating drives mesoscale evolution of ice rheology in the shear margins. Though we do not infer the existence of temperate ice in our study area, the importance of shear heating to ice rheology will be important in areas where temperate ice is present because interstitial liquid water has a pronounced softening effect on the ice. The importance of shear heating in driving along-flow variations in ice rheology highlights the potential for a thermomechanical feedback in glaciers that flow through bedrock channels - wherein faster ice flow softens ice through shear heating - that likely plays a role in ice-sheet evolution.

\section{ACKNOWLEDGMENTS}

We thank Carlos Martin, Robert Arthern, Jenny Suckale, Cooper Elsworth and James Rice for insightful conversations. We also thank two anonymous reviewers for helpful comments. B.M.M. was funded by an NSF Earth Sciences Postdoctoral Fellowship award EAR-1452587. C.R.M. was supported by an NSF Graduate Research Fellowship, award DGE1144152 and a David Crighton Fellowship. A.A.R. was funded through a NOAA Climate \& Global Change Postdoctoral Fellowship and the Caltech Stanback Postdoctoral Fellowship.

\section{REFERENCES}

Alley RB (1988) Fabrics in Polar Ice Sheets: Development and Prediction. Science, 240(4851), 493-495.

Alley RB (1992) Flow-law hypotheses for ice-sheet modeling. J. Glaciol., 38(129), 245-256.

Arthern RJ, Hindmarsh RCA and Williams CR (2015) Flow speed within the Antarctic ice sheet and its controls inferred from satellite observations. J. Geophys. Res.: Earth Surface, 120(7), 1171-1188.

Borstad CP and 6 others (2012) A damage mechanics assessment of the Larsen B ice shelf prior to collapse: toward a physically-based calving law. Geophys. Res. Lett., 39(18), 1-5I18502.

Bouchez JL and Duval P (1982) The fabric of polycrystalline ice deformed in simple shear: experiments in torsion, natural deformation and geometrical interpretation. Textures Microstruct., 5(3), 171-190.

Brinkerhoff DJ and Johnson JV (2015) Dynamics of thermally induced ice streams simulated with a higher-order flow model. J. Geophys. Res.: Earth Surface, 120(9), 1743-1770. (doi: 10.1002/2015JF003499)

Budd WF and Jacka TH (1989) A review of ice rheology for ice sheet modeling. Cold Reg. Sci. Technol., 16, 107-144.

Clarke GKC, Nitsan U and Paterson WSB (1977) Strain heating and creep instability in glaciers and ice sheets. Rev. Geophys. Space. Phys., 15(2), 235-247.

Clarke TS, Liu C, Lord NE and Bentley CR (2000) Evidence for a recently abandoned shear margin adjacent to ice stream B2, Antarctica, from ice-penetrating radar measurements. J. Geophys. Res., 105(B6), 13409-13422.

Cuffey KM and Paterson WSB (2010) The Physics of Glaciers. Elsevier, Boston, USA, 4th edition, chapter 3.

Cuffey KM and 5 others (2000a) Deformation properties of subfreezing glacier ice: Role of crystal size, chemical impurities, and rock particles inferred from in situ measurements. J. Geophys. Res., 105(B12), 27895-27915. 
Cuffey KM, Thorsteinsson T and Waddington ED (2000b) A renewed argument for crystal size control of ice sheet strain rates. J. Geophys. Res., 105(B12), 27889-27894.

Doake CSM and 7 others (2001) Rutford Ice Stream, In Alley RB and Bindschadler RA(eds.), The West Antarctic Ice Sheet: Behavior and Environment, Antarctica. American Geophysical Union, volume 77, 221-235. (doi: 10.1029/AR077p0221)

Dupont TK and Alley RB (2005) Assessment of the importance of iceshelf buttressing to ice-sheet flow. Geophys. Res. Lett., 32(4), 1-4.

Duval P (1977) The role of the water content on the creep rate of polycrystalline ice. Int. Assoc. Hydrol. Sci., 118, 29-33.

Echelmeyer KA, Harrison WD, Larsen C and Mitchell JE (1994) The role of the margins in the dynamics of an active ice stream. J. Glaciol., 40(136), 527-538.

Elsworth CW and Suckale J (2016) Rapid ice flow rearrangement induced by subglacial drainage in West Antarctica. Geophys. Res. Lett., 43(22), 11,697-11,707. (doi: 10.1002/2016GL070430)

Fowler AC and Johnson C (1996) Ice-sheet surging and ice-stream formation. Ann. Glaciol., 23, 68-73.

Fowler AC, Toja R and Vazquez C (2009) Temperature-dependent shear flow and the absence of thermal runaway in valley glaciers. Proc. R. Soc. A: Math. Phys. Eng. Sci., 466(2114), 363-382.

Fretwell P and 59 others (2013) Bedmap2: improved ice bed, surface and thickness datasets for Antarctica. Cryosphere, 7(1), 375-393. (doi: 10.5194/tc-7-375-2013)

Glen JW (1955) The creep of polycrystalline ice. Proc. R. Soc. London A, 228(1175), 519-538.

Goldsby DL and Kohlstedt DL (2001) Superplastic deformation of ice: Experimental observations. J. Geophys. Res.: Solid Earth, 106(B6), 11017-11030. (doi: 10.1029/2000JB900336)

Gudmundsson GH (2003) Transmission of basal variability to a glacier surface. J. Geophys. Res., 108(B5), 1-19.

Harrison WD, Echelmeyer KA and Larsen CF (1998) Measurement of temperature in a margin of Ice Stream B, Antarctica: implications for margin migration and lateral drag. J. Glaciol., 44(148), 615624. (doi: 10.1017/S0022143000002112)

Haseloff M, Schoof CG and Gagliardini O (2015) A boundary layer model for ice stream margins. J. Fluid Mech., 781, 353-387.

Herron SL and Langway CC (1982) A Comparison of Ice Fabrics and Textures at Camp Century, Greenland and Byrd Station, Antarctica. Ann. Glaciol., 3, 118-124. (doi: 10.3189/ S0260305500002639)

Hewitt IJ and Schoof CG (2017) Models for polythermal ice sheets and glaciers. Cryosphere, 11(1), 541-551.

Hindmarsh RCA (2004) Thermoviscous stability of ice-sheet flows. J. Fluid Mech., 502, 17-40. (doi: 10.1017/S0022112003007390)

Hindmarsh RCA (2006) Stress gradient damping of thermoviscous ice flow instabilities. J. Geophys. Res.: Solid Earth, 111(B12) (doi: 10.1029/2005JB004019)

Hindmarsh RCA (2009) Consistent generation of ice-streams via thermo-viscous instabilities modulated by membrane stresses. Geophys. Res. Lett., 36(6), 1-6,106502.

Hindmarsh RCA and Stokes CR (2008) Formation mechanisms for ice-stream lateral shear margin moraines. Earth Surf. Process. Landf., 33(4), 610-626.

Hudleston PJ (1977) Progressive Deformation and Development of Fabric Across Zones of Shear in Glacial Ice Springer: Berlin Heidelberg, 121-150. (doi: 10.1007/978-3-642-86574-9_7)

Hudleston PJ (2015) Structures and fabrics in glacial ice: A review. J. Struct. Geol., 81(C), 1-27.

Jacka T and Budd W (1989) Isotropic and anisotropic flow relations for ice dynamics. Ann. Glaciol., 12(1), 81-84. (doi: 10.3198/ 1989AoG12-1-81-84)

Jacka TH (1984) Laboratory studies on relationships between ice crystal size and flow rate. Cold Reg. Sci. Technol., 10(1), 31-42.

Jackson M and Kamb B (1997) The marginal shear stress of Ice Stream B, West Antarctica. J. Glaciol., 43(145), 415-426.

Jacobson HP and Raymond CF (1998) Thermal effects on the location of ice stream margins. J. Geophys. Res., 103(B6), 12111 12122.
Jezek KC, Curlander JC, Carsey F, Wales C and Barry RG (2013) RAMP AMM-1 SAR Image Mosaic of Antarctica. Version 2. Technical report, National Snow and Ice Data Center, Boulder, Colorado USA (doi: 10.5067/8AF4ZRPULS4H).

Joughin I, MacAyeal D and Tulaczyk S (2004) Basal shear stress of the Ross ice stream from control method inversions. J. Geophys. Res., 109(B09405), 1-20. (doi: 10.1029/2003JB002960)

Joughin I and 5 others (2006) Integrating satellite observations with modelling: basal shear stress of the Filcher-Ronne ice streams, Antarctica. Philos. Transac. R. Soc. A: Math. Phys. Eng. Sci., 364(1844), 1795-1814.

Joughin I, Alley RB and Holland DM (2012) Ice-Sheet Response to Oceanic Forcing. Science, 338(6111), 1172-1176. (doi: 10.1126/science.1226481)

Joughin I, Smith BE and Medley B (2014) Marine ice sheet collapse potentially under way for the Thwaites Glacier Basin, West Antarctica. Science, 344(6185), 735-738. (doi: 10.1126/ science.1249055)

Kyrke-Smith TM, Katz RF and Fowler AC (2013) Subglacial hydrology and the formation of ice streams. Proc. R. Soc. London A: Math. Phys. Eng. Sci., 470(2161), 1-22 (doi: 10.1098/rspa.2013.0494)

Lipovsky BP and Dunham EM (2017) Slow-slip events on the whillans ice plain, antarctica, described using rate-and-state friction as an ice stream sliding law. J. Geophys. Res.: Earth Surface, 122(4), 973-1003. (doi: 10.1002/2016JF004183), 2016JF004183

Lliboutry L and Duval P (1985) Various isotropic and anisotropic ices found in glaciers and polar ice caps and their corresponding rheologies. Ann. Geophys., 3(2), 207-224.

Ma Y and 5 others (2010) Enhancement factors for grounded ice and ice shelves inferred from an anisotropic ice-flow model. J. Glaciol., 56(199), 805-812. (doi: 10.3189/002214310794457209)

MacAyeal D (1989) Large-scale ice flow over a viscous basal sediment - theory and application to ice stream-B, Antarctica. J. Geophys. Res., 94(B4), 4071-4087.

MacAyeal D (1993) A tutorial on the use of control methods in icesheet modeling. J. Glaciol., 39(131), 91-98.

Macayeal DR, Rignot E and Hulbe CL (1998) Ice-shelf dynamics near the front of the Filchner-Ronne Ice Shelf, Antarctica, revealed by SAR interferometry: model/interferogram comparison. J. Glaciol., 44(147), 419-428.

Meyer CR and Hewitt IJ (2017) A continuum model for meltwater flow through compacting snow. Cryosphere, 11(6), 27992813. (doi: 10.5194/tc-11-2799-2017)

Meyer CR, Fernandes MC, Creyts TT and Rice JR (2016) Effects of ice deformation on Röthlisberger channels and implications for transitions in subglacial hydrology. J. Glaciol., 62(234), 750-762. (doi: 10.1017/jog.2016.65)

Meyer CR, Hutchinson JW and Rice JR (2017) The path-independent Mintegral implies the creep closure of englacial and subglacial channels. J. Appl. Mech., 84(1), 011006-1-9. (doi: 10.1115/1.4034828)

Minchew BM, Simons M, Hensley S, Björnsson H and Pálsson F (2015) Early melt-season velocity fields of Langjökull and Hofsjökull ice caps, central Iceland. J. Glaciol., 61(226), 253266. (doi: 10.3189/2015JoG14J023)

Minchew BM and 6 others (2016) Plastic bed beneath Hofsjökull Ice Cap, central Iceland, and the sensitivity of ice flow to surface meltwater flux. J. Glaciol., 62(231), 147-158. (doi: 10.1017/ jog.2016.26)

Minchew BM, Simons M, Riel BV and Milillo P (2017) Tidally induced variations in vertical and horizontal motion on Rutford Ice Stream, West Antarctica, inferred from remotely sensed observations. J. Geophys. Res.: Earth Surf., 122, 167-190. (doi: 10.1002/2016JF003971)

Morlighem M, Seroussi H, Larour E and Rignot E (2013) Inversion of basal friction in Antarctica using exact and incomplete adjoints of a higher-order model. J. Geophys. Res.: Earth Surf., 118(3), 1746-1753. (doi: 10.1002/jgrf.20125)

Mottram R and Benn DI (2009) Testing crevasse-depth models: a field study at Breid. h. amerkurjokull, Iceland. J. Glaciol., 55 (192), 746-752. 
Mouginot J, Rignot E and Scheuchl B (2014) Sustained increase in ice discharge from the Amundsen Sea Embayment, West Antarctica, from 1973 to 2013. Geophys. Res. Lett., 41(5), 1576-1584. (doi: 10.1002/2013GL059069)

Nye JF (1957) The distribution of stress and velocity in glaciers and ice-sheets. Proc. R. Soc. London A, 239(1216), 113-133.

Ockendon H (1979) Channel flow with temperature-dependent viscosity and internal viscous dissipation. J. Fluid Mech., 93(04), 737-746.

Payne AJ and 10 others (2000) Results from the EISMINT model intercomparison: the effects of thermomechanical coupling. J. Glaciol., 46(153), 227-238. (doi: 10.3189/172756500781832891)

Pearson JRA (1977) Variable-viscosity flows in channels with high heat generation. J. Fluid Mech., 83(01), 191-206.

Perol T and Rice JR (2015) Shear heating and weakening of the margins of west antarctic ice streams. Geophys. Res. Lett., 42(9), 3406-3413. (doi: 10.1002/2015GL063638), , 2015GL063638

Perol T, Rice JR, Platt JD and Suckale J (2015) Subglacial hydrology and ice stream margin locations. J. Geophys. Res.: Earth Surf., 120(7), 1352-1368, ISSN 2169-9011 ( doi: 10.1002/ 2015JF003542), 2015JF003542

Raymond C (1996) Shear margins in glaciers and ice sheets. J. Glaciol., 42(140), 90-102.

Raymond CF, Echelmeyer KA, Whillans IM and Doake CSM (2001) Ice stream shear margins, 137-155. American Geophysical Union (doi: 10.1029/AR077p0137)

Rignot E, Mouginot J and Scheuchl B (2011) Ice Flow of the Antarctic Ice Sheet. Science, 333(6048), 1427-1430. (doi: 10.1126/ science.1208336)

Robel AA, DeGiuli E, Schoof CG and Tziperman E (2013) Dynamics of ice stream temporal variability: Modes, scales, and hysteresis. J. Geophys. Res.: Earth Surf., 118(2), 925-936. (doi: 10.1002/ jgrf.20072)

Robel AA, Schoof CG and Tziperman E (2014) Rapid grounding line migration induced by internal ice stream variability. J. Geophys. Res.: Earth Surf., 119(11), 2430-2447. (doi: 10.1002/2014JF003251)

Robel AA, Schoof C and Tziperman E (2016) Persistence and variability of ice-stream grounding lines on retrograde bed slopes. Cryosphere, 10(4), 1883-1896. (doi: 10.5194/tc-10-1883-2016)

Robin GQ (1955) Ice movement and temperature distribution in glaciers and ice sheets. J. Glaciol., 2(18), 523-532.

Scambos TA, Echelmeyer KA, Fahnestock MA and Bindschadler RA (1994) Development of enhanced ice flow at the southern margin of Ice Stream D, Antarctica. Ann. Glaciol., 20, 313-318.

Scambos TA, Bohlander JA, Shuman CA and Skvarca P (2004) Glacier acceleration and thinning after ice shelf collapse in the Larsen B embayment, Antarctica. Geophys. Res. Lett., 31(18), 1-4 (doi: 10.1029/2004GL020670)

Schoof C (2004) On the mechanics of ice-stream shear margins. J. Glaciol., 50(169), 208-218.

Schoof C (2012) Thermally driven migration of ice-stream shear margins. J. Fluid Mech., 712, 552-578. (doi: 10.1017/jfm.2012.438)

Schoof C and Hewitt I (2013) Ice-sheet dynamics. Annu. Rev. Fluid Mech., 45(1), 217-239. (doi: 10.1146/annurev-fluid-011212140632)

Schoof C and Hewitt IJ (2016) A model for polythermal ice incorporating gravity-driven moisture transport. J. Fluid Mech., 797, 504-535. (doi: 10.1017/jfm.2016.251)
Schulson EM and Duval P (2009) Creep and Fracture of Ice. Cambridge, England: Cambridge University Press.

Smith EC and 6 others (2017) Ice fabric in an Antarctic ice stream interpreted from seismic anisotropy. Geophys. Res. Lett., 38 (7596), 245-249.

Stokes CR and Clark CD (2002) Ice stream shear margin moraines. Earth Surf. Process. Landf., 27(5), 547-558. (doi: 10.1002/ esp.326)

Suckale J, Platt JD, Perol T and Rice JR (2014) Deformation-induced melting in the margins of the West Antarctic ice streams. J. Geophys. Res.: Earth Surf., 119(5), 1004-1025. (doi: 10.1002/ 2013JF003008)

Thompson J, Simons M and Tsai VC (2014) Modeling the elastic transmission of tidal stresses to great distances inland in channelized ice streams. Cryosphere, 8(6), 2007-2029. (doi: 10.5194/ tc-8-2007-2014)

Van der Veen CJ (1998a) Fracture mechanics approach to penetration of bottom crevasses on glaciers. Cold Reg. Sci. Technol., 27, 213-223.

Van der Veen CJ (1998b) Fracture mechanics approach to penetration of surface crevasses on glaciers. Cold Reg. Sci. Technol. 27, 31-47.

van Wessem JM and 13 others (2014) Improved representation of East Antarctic surface mass balance in a regional atmospheric climate model. J. Glaciol., 60(222), 761-770.

Vaughan DG (1993) Relating the occurrence of crevasses to surface strain rates. J. Glaciol., 39(132), 255-266.

Vaughan MJ and 5 others (2017) Insights into anisotropy development and weakening of ice from in situ $\mathrm{P}$ wave velocity monitoring during laboratory creep. J. Geophys. Res.: Solid Earth, 122 (9), 7076-7089. (doi: 10.1002/2017JB013964), 2017JB013964

\section{APPENDIX: GLEN'S LAW}

The constitutive relation for ice (Eq. 1) is commonly given in terms of effective stress and strain rate such that (Glen, 1955; Cuffey and Paterson, 2010)

$$
\dot{\varepsilon}_{\mathrm{e}}=E A_{0} \tau_{\mathrm{e}}^{n}
$$

where $\dot{\varepsilon}_{e}=\sqrt{\dot{\varepsilon}_{i j} \dot{\varepsilon}_{i j} / 2}$ (in summation notation) is the square root of the second invariant of the strain rate tensor $\dot{\boldsymbol{\varepsilon}}$, known as the effective strain rate, and $\tau_{\mathrm{e}}=\sqrt{\tau_{i j} \tau_{i j} / 2}$ is the square root of the second invariant of the deviatoric stress tensor $\boldsymbol{\tau}$, known as effective stress. To understand the relative contribution of each term in the strain rate tensor, we define a right-hand coordinate system oriented such that $x$ is along the flow vector, $y$ points across flow in the horizontal plane, and $z$ points down. When shearing is dominant, as it is everywhere in our study area (Minchew and others, 2017), $\dot{\varepsilon}_{\mathrm{e}} \approx \dot{\varepsilon}_{\text {lat }}$, where $\dot{\varepsilon}_{\text {lat }}=\left|\dot{\varepsilon}_{x y}\right|=\left|\partial u_{x} / \partial y\right| / 2$ and $\tau_{\mathrm{e}} \approx \tau_{\text {lat, }}$, where $\tau_{\text {lat }}=\left|\tau_{x y}\right|$. Therefore, Eqn. (1) is a reasonable approximation of the constitutive relation (Eqn (A1)) in areas where shearing dominates the stress field. 